\title{
Research of the Class Cohesion of Group Psychological Counseling in the College freshmen
}

\author{
Min $\mathrm{Xu}^{1, \mathrm{a},{ }^{*}}$, Guangyun Wang ${ }^{2, \mathrm{~b}}$ \\ ${ }^{1}$ Institute of Information Science and Engineering,Zaozhuang College, China \\ ${ }^{2}$ Institute of Information Science and Engineering,Zaozhuang College, China \\ a170303726@qq.com, 2631595302@qq.com \\ ${ }^{*}$ Corresponding author
}

Keywords: Class cohesion; College freshmen; Group psychological counseling.

\begin{abstract}
Establishing a unified and orderly class with strong cohesion after admission of college freshmen to college is the focus of entrance education, class construction and moral education in college. Class cohesion is the mutual attraction of class attraction to students and attraction between students, which is beneficial to the construction of class atmosphere, style of study and school spirit, and can promote physical and mental health of college students. This paper explores the association between group psychological counseling and class cohesion, and designs group psychological counseling program for college freshmen from four aspects which are goal definition, theoretical basis, participants and structure arrangement.
\end{abstract}

\section{团体心理辅导在大学新生班级凝聚力的研究 \\ 徐敏 $1, a,{ }^{*}$;王广云 $2, b$ \\ 1本庄学院信息科学与工程学院, 苯庄, 山东, 中国 \\ 2冭庄学院信息科学与工程学院, 麥庄, 山东, 中国 \\ a170303726@qq.com, 2631595302@qq.com \\ 通讯作者}

关键词: 班级凝聚力; 新生; 团体心理辅导

中文摘要.大学新生入校后建立一个团结有序, 凝聚力强的班集体是高校入学教育、班集体建 设和德育工作的重点。班级凝聚力是班级对学生的吸引力和学生之间的相互吸引力, 有利于 班风、学风和校风的建设, 促进大学生的身心健康。本文探索团体心理辅导与班级凝聚力之 间的关联, 从目标明确、理论依据、参与人员及结构安排四个方面来设计大学新生的班级凝 聚力的团体心理辅导方案。

\section{1. 引言}

大学生职业生涯规划是动态的过程, 影响人的整个生命历程, 指大学生结合自身情况和 外部工作世界, 为自己确立职业方向、职业目标, 为实现职业生涯目标而制定行动时间和方 案, 实现人生价值。以 “班级凝聚力” 为关键词, 在CNKI搜得文献 8577 篇, 以 “大学生”、 “班级凝聚力”，搜得 28 篇，以“大学新生”、“团体心理辅导”、“班级凝聚力” 搜得 2 篇。凝聚力的研究国外起步较早, 形成了系统的研究范式, 研究对象主要为运动团体、军事 
团体或企业团体, 以普通学生较少; 国内大部分研究是借鉴西方管理理论进行的定性分析, 如现状描述、调查分析和影响因素等, 少部分研究是定量分析, 如量表的编制。

\section{2. 班级凝聚力和团体心理辅导的概念}

教育学家魏书生曾说过 “班级就像一个大家庭, 同学们如兄弟姐妹般互相关心着, 帮助 着, 互相鼓舞着, 照顾着, 一起长大了, 成熟了, 便离开这个家庭, 走向了社会” ; 苏霍姆 林斯基也曾说过 “集体是教育的工具”。凝聚力最早由Kurt Lewin指出，“凝聚力主要关注 个体如何知觉其自身与某个特定群体的关系” , 后来凝聚力也被称为群体凝聚力, 指群体对 成员以及群体内成员与成员之间的吸引和群体内成员愿意分担群体目标的程度。简而言之, 班级凝聚力是班级对学生的吸引力和学生之间的相互吸引力。班级作为高校开展教育、教学 的基本单位和载体, 不是简单的个体组合, 而是有组织的群体, 班级凝聚力的强弱是衡量班 集体质量的重要指标。

人是高级社会动物, 成长离不开团体, 团体对人的成长发展起着至关重要的作用, 人只 有作为团体的一份子, 需求和期望才能得到满足, 尤其是大学新生处于价值观形成的关键期, 需要、观念与行为易受团体的影响。团体心理辅导是通过团体内人际交互作用, 促进个体在 交往中通过观察、学习、体验, 认识自我、探索自我、接纳自我, 调整改善与他人的关系, 学习新的态度与行为方式, 以发展良好适应的助人过程。特色在于培养人的信任感和归属感, 感染力强, 影响广泛，如对团体的信任扩展到对周围其他人的信任。

\section{3. 班级凝聚力和团体心理辅导的关联}

大学生处于自我意识形成和价值观形成的关键期, 大学新生的成长和发展易受班级其他 同学的影响, 班级凝聚力的建设以班级共同活动为中介。如果对班级制度和管理认可, 处在 充满信任、理解、包容和爱的班集体, 不仅对自身的学习和生活起着积极作用, 激发自身潜 能、知情意一致, 促进新生的身心健康发展, 还能潜移默化增强新生之间的人际交往能力、 团体合作意识和集体荣誉感。如果处在充满冲突、矛盾、猜疑、彼此不合作和 “硝烟弥漫” 的班集体, 不利于新生的学习和生活, 妨碍身心健康发展, 人际交往能力、团体合作意识和 活动效率等都会受到影响。

心理学家勒温提出团体动力学理论, 把人的心理和行为视为一种场的现象, 场具有复杂 的非物理的力及它们之间错综复杂的变化, 而这种变化所产生的动力结构使场成为动力场, 随着动力场的千变万化, 人的心理和行为也随之变化, 函数式 $\mathrm{B}=\mathrm{f}(\mathrm{PE}), \mathrm{B}$ 代表行为, $\mathrm{P}$ 代表个 人, $\mathrm{E}$ 代表环境, 行为是个人内心及所处的环境相互作用。此理论为团体心理辅导提供了理论 支持, 如果创建一种充满理解、尊重、和谐、温暖的团体氛围, 潜移默化会影响到团体中每 位成员，使成员具有强烈的归属感、安全感和荣誉感等，促进成员自身成长发展，团体凝聚 力自然而然增强。

班级凝聚力和团体心理辅导都是培养团队精神, 建立大学生社会资本的需要, 促进大学 生的成长发展, 增强大学生集体归属感。刚踏入高校的新生对自己的班集体充满着热情和憧 憬, 非常乐意为新成立的班集体奉献自己的力量, 却不知该如何去做, 因此, 班级凝聚力具 有明确的导向、整合和育人的功能, 对大学生起着巨大的潜移默化的教育和激励作用, 尤其 大学新生, 掌握新生的心理特征, 抓住时机, 开展相应的团体心理辅导活动, 效果会更加显 著。

\section{4. 大学新生班级凝聚力的团体心理辅导的方案制定}

团体方案的制定是开展团体心理辅导最基本也是最核心部分，直接影响活动的最终效果。 团体方案制定为: 团体性质与团体名称、团体目标、团体领导者、团体对象与规模、团体活 
动时间及频率、理论依据及参考资料、团体活动的场所、团体评估方法等。笔者认为制定适 合大学新生班级凝聚力的团体心理辅导方案, 主要从以下四个方面来设计: 目标明确、理论 依据、参与人员及结构安排。

\section{1 大学新生班级凝聚力团体方案的目标明确}

建设班级凝聚力的条件和方向是班级具有共同目标，共同目标与个体目标或多数人利益 一致时, 班级学生会自然紧密联系在一起, 彼此之间的个人利益冲突在共同目标面前会被淡 化。新生班级凝聚力的团体心理辅导方案首先应具有明确目标, 目标需得到班级多数同学的 赞同与认可。

本方案活动的总目标（班级共同目标）是提升大学新生班级凝聚力的水平，总目标又分 多个阶段目标, 每个阶段目标要具有关联性和连贯性, 为总目标奠定牢固的基础, 最终循序 渐进地实现总目标, 目标的实现需要学生的密切协作和共同努力, 形成协调一致的合力。查 阅文献, 有些班级凝聚力的团体辅导方案里面的阶段目标与总目标无关联性与连贯性, 这样 会影响最终效果。马斯洛的需要层次理论, 人具有五种需要, 需要层次是逐渐上升, 只有低 级需要得到满足后才会追求高级需要, 对此方案启示是每阶段目标或活动不仅要循序渐进, 还要有关联性, 不能随便做, 只要他们内心深处感受到温暖和爱, 会真诚的表达想法和情感, 逐渐增强大学新生的集体归属感。

\section{2 大学新生班级凝聚力团体方案的理论依据}

部分团体心理辅导方案的理论依据只参考团体心理咨询的理论, 忽略凝聚力的影响因素 或理论, 毕竟团体心理辅导是手段, 目的与核心是提升班级凝聚力的水平, 因此, 方案制定 的理论依据既要考虑团体心理咨询的理论, 也要考虑班级凝聚力的理论, 找到彼此之间的关 联, 以此为切入点, 促进活动顺利完成, 达到预期的效果。

凝聚力的影响因素, 研究者各抒己见, 从不同的维度来研究凝聚力, 熊娇《基于大学生 评价的班级凝聚力特征研究》班级凝聚力有五个维度分别为: 组织认同、管理支持、人际和 谐、集体参与和团体业绩; 刘慧珍《兰州市初中班级团体凝聚力现状调查与研究》中认为有 六项分别为: 班级目标及期望的一致性程度、班级成员对规范的认同及内化程度、班级团体 领导方式民主程度、班级团体人际关系亲密和谐程度、班级团体心理气氛信赖支持程度和班 级团体意识的强度等。笔者从团体心理辅导和班级管理的角度出发, 认为班级凝聚力的特征 分主客观两因素, 主观因素为学生和领导者两个方面, 客观因素为班级共同目标、班级规模 人数、班级管理制度和班级活动四个方面。

团体动力学理论强调团体成员之间的关系和行为是通过团体各部分力量作用于个体来起 作用, 对团体心理辅导和班级凝聚力的启示是集体对个体的影响力, 因此, 活动游戏的设计 尽可能为合作性, 使新生意识到团体合作的重要性, 此方案制定的理论依据要把两种理论都 考虑进去, 找到结合点, 既利于团体心理活动的顺利进行, 又利于班级凝聚力的提升, 更利 于大学生的成长与发展。

\section{3 大学新生班级凝聚力团体方案的参与人员}

参与人员指领导者 (辅导员) 和大学新生, 领导者是整个团体的灵魂, 起着组织和指导 的作用, 关系着团体方案的成败; 大学新生是团体对象, 掌握新生的心理特、共性和个性。 辅导员以团体心理辅导活动为手段, 加深对学生的了解与师生关系, 增强同学之间情感交流, 促进新生快速的适应大学。

领导者由本班辅导员（班主任）担任，而不是助理辅导员或学生干部担任，辅导员在班 级凝聚力的建设中起主导作用, 利于师生之间交流, 决定班级凝聚力的水平。辅导员首先应 具备人格魅力, 清晰的自我认识, 了解自我、接纳自我并欣赏自我, 对学生的状态做出正确 的判断及相应的回应; 其次, 内心深处热爱与学生打交道, 与不同类型的大学生建立良好的 
关系, 易做到尊重、热爱和接纳每个大学生; 再次, 加强学习与总结, 不断地完善和充实自 己, 提高自身能力, 掌握大学生心理健康相关知识和沟通技巧等新知识; 最后, 必须经过专 业的团体辅导培训, 熟知团体心理咨询理论, 掌握基本的领导技巧, 善于运用支持、指导、 鼓励、同理等技巧, 了解团体辅导过程中领导者的角色与职责, 参与并影响团体发展, 妥善 处理团体辅导中出现的各种问题。

大学新生的个性化、自主化，多元化（知识、思想、需求），独立性和批判性明显增强。 刚踏入高校, 面对一个全新的世界, 无论环境还是学习等存在巨大变化, 新生或多或少具有 陌生感、紧张感和焦虑情绪。新生要尽快认清和调整状态、转变角色, 适应大学生活。研究 证明, 大一班级凝聚力最高, 随着年级增长有明显的下降趋势, 因此, 大学新生不仅是自身 发展的关键期, 也是班级凝聚力形成的关键期, 在新生入学时以相关的团体心理辅导活动为 手段, 能有效地提升班级凝聚力。在新生时期把班级凝聚力抓起来, 利于新生自身更快适应 大学生活, 促进班风学风建设, 对今后成长发展起着无形的积极作用, 如果抓不起来, 在后 期需要付出更多的精力、努力和时间才有可能建立起同样的效果。

\section{4 大学新生班级凝聚力的团体方案的结构安排}

团体方案制定最好不低于八次，每次120-150分钟，每次团体活动的结构安排应具有热身 活动、活动主题、分享与总结和布置家庭作业四个部分, 其中, 活动主题是主要部分, 分享 与总结是关键, 团体活动的最终目的不是游戏的玩法, 而是玩后成员之间的反思和讨论。

查阅文献，发现班级凝聚力的结构安排存在以下缺点：没有针对性，易忽略团体成员的 特点, 如性别和年龄等, 班级女生居多, 选择 “突围闯关” 游戏等, 强烈的动作游戏不适 合女生, 也吸引不了学生的兴趣, 反之亦然; 阶段活动与班级凝聚力的一致性较差, 选择游 戏勉强能用, 但对凝聚力的提升效果不显著, 如选价值观或挫折之类的游戏, “生存选择” 或 “举手” 等; 热身活动繁琐复杂, 如 “无家可归” 等, 热身活动是每次活动主题的前奏, 最好选择简单、吸引新生兴趣, 又能对班级凝聚力提升奠定基础。

此方案的结构安排中活动主题选择至关重要，应根据新生的心理特征、现状、凝聚力的 理论等, 选择应满足学生的需要、唤起新生参与的兴趣和积极性、具有可操作性, 班级凝聚 力自然而然的提升，反之亦然。

建设优秀班集体以班级凝聚力作后盾, 班级凝聚力的强弱直接关系到大学生的成长, 是 无形的却产生有形的力量。一套完整有效的班级凝聚力团体心理辅导方案, 需要领导者有健 全的人格和相关的知识技巧; 需要班级凝聚力和团体心理辅导等相关理论做依据, 不是简单 游戏的拼凑组合在一起; 需要静心仔细的设计结构安排, 考虑每次活动主题、地点、成员、 安全、游戏性质等各种因素, 才能设计出适合又独特的新生班级凝聚力的团体方案。并以此 方案为手段, 在新生中开展, 快速的消除新生之间的陌生感, 增强人际交往、团体合作意识 和集体归属感, 促进班级凝聚力的形成, 促进班风、学风、校风的建设, 促进教学质量、教 育与管理工作的开展。

\section{致谢}

本文为2016年度苯庄学院学生思想教育与管理研究项目《团体心理辅导在大学新生班级凝 聚力的研究》的结果性成果。

\section{References}

[1] Fumin Fan, Group Counseling[M], Beijing: Higher Education Press, 2005.

[2] Xiong Jiao, The Study of Classes' Cohesion Based on the Evaluation of College Students[D], Chongqing University, pp.22-24,2010. 
[3] Liu Huizhen, Investigation and Research on Class Cohesiveness at Junior High School in L anZhou City[D], Northwest Normal University,pp. 18-20, 2002.

[4] Xu Min, The Research about the Construction Class Cohesion of College Students, Journal of Zao Zhuang University, 30 (4) : 100-102,2013.

[5] Zhu Lifang, Applied Research about Class Group Counseling at University Freshmen’ s Class Construction, Journal of Zhejiang Ocean University(Humanities Science),32(2), pp.72-75,2015. 